\title{
Cross-sectional study for assessment of fish consumption in terms of the level of physical activity and perception of quality of life in volunteers in Brazil and Portugal
}

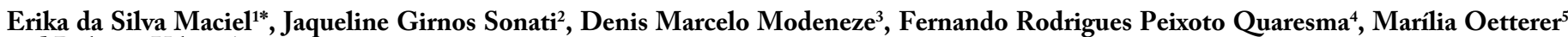
and Roberto Vilarta ${ }^{6}$

${ }^{1}$ Professor at the Lutheran University Center of Palmas (CEULP-ULBRA), Brazil

${ }^{2}$ Pos doctor at Nursing School, State University of Campinas (UNICAMP), Campinas, São Paulo, Brazil

${ }^{3}$ Dsc. State University of Campinas (UNICAMP), Campinas, São Paulo, Brazil

${ }^{4} \mathrm{PhD}$ student in the Department of Health Collective, Design of Laboratory Studies and Scientific Writing, School of Medicine of ABC, Santo André, SP, Brazil ${ }^{5}$ Titular Professor at the Department of Agroindustry, Food and Nutrition, "Luiz de Queiroz" College of Agriculture, University of São Paulo, SP, Brazil

${ }^{6}$ Titular Professor at Faculty of Physical Education, State University of Campinas (UNICAMP) Campinas, São Paulo, Brazil

\begin{abstract}
Background: A healthier lifestyle, with the promotion of physical activity and healthy diets, has supported studies on the possible relationship of daily choices for food consumption and practices of physical activities, this research aimed to evaluate the relationship between the frequency of fish consumption, the level of physical activity and domains of quality of life in the voluntaries from the Brazil and Portugal.

Methods: This is a cross-sectional delineation study through a survey conducted via the Internet, the volunteers responded to a structured survey about fish consumption, the perception of quality of life was evaluated with WHOQOL-bref and the level physical activity with International Physical Activity Questionnaire all instruments available through the online system SurveyMonkey. For data analysis, the criterion adopted was the situation of the subjects who reported consuming fish at least once a week (Group 1) or less than once a week or who did not consume fish (Group 2). As a non-parametric test, the Mann-Whitney test was used For the comparison of average values of variables.

Results: The criterion adopted was the situation of the subjects who reported consuming fish at least once a week (Group 1 , $\mathrm{n}=417)$ or less than once a week or who did not consume fish (Group 2, n = 527). The results showed significant statistical differences between the consumption groups in all variables considered The values for the mean and sum of ranks show that Group1, formed by volunteers with higher fish consumption, presents higher values in all variables, indicating that more frequent fish consumers have a more active lifestyle and better perception of quality of life in both countries.

Conclusions: The results suggest the fish consumption appears to be associated to more active and better perception of quality of life, regardless of geographical location, so is so important actions encouraging the consumption of healthier foods, like a fish, and regular physical activities in worldwide.
\end{abstract}

\section{Introduction}

The interest in a healthier lifestyle, with the promotion of physical activity and healthy diets, has supported studies on the possible relationship of daily choices for food consumption [1,2].

Everyday choices include intrinsic and extrinsic elements. Regarding foods, intrinsic choices concern their nutritional value, the presence of functional component, palatability and the relationship with health. Extrinsic elements, on the other hand, refer to ecofriendly, sustainable and organic production, and the use of techniques that ensure animal welfare [3]. It has been observed that intrinsic motivation is critical for the general maintenance of the practice of physical activity and a balanced diet [1].

In this sense, attitudes regarding fish consumption have been linked to health issues, the main drive for consumers' interest [4]. The traditional diet pattern of Mediterranean populations, for example, rich in fish consumption, has been evidenced as a health promoter, and consistent investigations have been conducted on this type of diet [5-7].

In the Mediterranean countries, the frequency of fish consumption is very high, regardless of barriers and motivational aspects that affect its consumption [8]. The interest in fish consumption is connected with information about its nutritional value and its association with health improvement. This aspect is observed in populations that have a fish-based diet [9-11] and consume fish at least twice a week, according to nutritional recommendations $[12,13]$.

Despite the cultural differences, a study conducted on fish

Correspondence to: Erika da Silva Maciel, Post-doctor at University of São Paulo, Court 106 South 3rd mall lot 21 Block A fit 502, Palmas, 7702074, SP, Brazil; E-mail: erikasmaciel@gmail.com

Received: March 12, 2016; Accepted: April 05, 2016; Published: April 08, 2016 
consumers in Belgium, Denmark, the Netherlands, Poland and Spain showed that, in general, there is a concern among consumers with the relationship between food and health, in addition to a positive association of fish consumption with health benefits and a subjective perception of life satisfaction [14].

There seems to be a collective consciousness to food healthiness, where fish has gained prominence due to studies that reinforced the association of fish consumption with lower prevalence of nontransmittable chronic diseases such as diabetes [7-15], heart conditions [6-16], breast cancer [6], reduction of cholesterol levels and stroke incidence, and Alzheimer's disease. Fish consumption is also attributed to increased cognitive function in adults and prevention of birth of underweight babies [10].

A study conducted in Norway, showed that women who consume from 75-100 g of lean fish, between 2-3 times a week, presented a reduction of approximately $30 \%$ of the risk for type II diabetes (Rylander et al. 2014). An increase in fish consumption to about $14.4 \mathrm{~g} /$ day was associated with a decreased prevalence of metabolic syndrome [17].

Despite several well-known benefits, fish consumption is still low in many countries and it may be linked to cultural differences [18], influences in social group [19], preparation convenience [20], high prices and problems in the production chain [21]. In Brazil, the low per capita fish consumption result from the fact that few people have the habit of consuming fish in their usual diet [22].

The regular practice of physical activity has been recommended as one of the factors capable of decreasing mortality rates and controlling diseases such as hypertension, diabetes and obesity worldwide $[23,24]$. Physical activity provides the population benefits for the improvement or maintenance of health conditions, which bring benefits to public health systems in terms of hospitalizations and complementary services [25]. Adequate diets, along with healthy lifestyles, can be even more beneficial, demonstrating the importance of expanding knowledge about the effects of this association on the quality of life (QOL) of the population [1].

In light of these considerations, this research aimed to evaluate the relationship between the frequency of fish consumption, the level of physical activity and domains of QOL recommended by the World Health Organization (WHO), in the context of two countries, Brazil and Portugal.

\section{Methods}

This is a cross-sectional delineation study through a survey conducted via the internet.

\section{Subjects}

This research counted on the participation of 944 Brazilians and 132 Portuguese volunteers who responded to a structured survey available through the online system Survey Monkey.

For data analysis, the criterion adopted was the situation of the subjects who reported consuming fish at least once a week (Group 1, $\mathrm{n}=417$ ) or less than once a week or who did not consume fish (Group $2, \mathrm{n}=527)$.

The instruments were available in two versions, one for disclosure in Brazil and another in Portugal with semantic language adaptations carried out by language specialists in Portugal. In Brazil, the survey was made available on the homepage of the University of São Paulo (USP), the Brazilian Enterprise for Agricultural Research (EMBRAPA) and federal universities, and the access was allowed to any Brazilian resident in the country. In Portugal, the invitation was forwarded to researchers and students of the University of Porto, and access was granted to any Portuguese citizen.

All participants were asked to read and agree to the Free Informed Term of Consent (FITC) made available on the homepage of the survey. This study was approved by the Committee of Ethics for research with human beings of the Escola Superior de Agricultura "Luiz de Queiroz" of the University of São Paulo, under the protocol number 087.

\section{Fish consumption}

The study on consumption of fish was carried out using the Perception Survey of Fish Consumption developed and validated by Maciel [26] with adaptations. The questionnaire consisted of evaluating the frequency and consumption habits, desirable characteristics or attributes and purchase-related habits of fish.

\section{Quality of life (QOL)}

The perception of QOL was evaluated with WHOQOL-bref [27], which covers four domains - physical, psychological, social relations and environment - and the general QOL.

\section{Physical activity level}

The level of physical activity was verified by the International Physical Activity Questionnaire (IPAQ) short version and normal week validated in Brazil [28].

The results were calculated on the basis of the MET (Metabolic Equivalent) that refer to the quantity of oxygen required, per minute, under conditions of normal rest, equal to $3.5 \mathrm{ml}$ of oxygen consumed per kilogram of body weight per minute $(\mathrm{ml} / \mathrm{kg} \mathrm{min})$. The higher the MET, the greater oxygen consumption, thus, the greater calorie burning [29].

\section{Data analyses}

We compared variables of domains of QOL and MET values recommended for a normal week between the two groups composed of subjects of both countries, but also allowing differentiated analyses of responses given by respondents in each country. The data were subjected to the analysis of normality (Kolmogorov and Smirnoff tests) and homoscedasticity. The descriptive analysis of the sample was performed.

For the comparison of average values of variables to categorize fish consumption, the validity of the application of nonparametric tests was defined due to the ordinal nature of the data and the inadequate application of the analysis of variance, supported by the non-adherence of data original to normal distribution. As a non-parametric test, the Mann-Whitney test was used.

\section{Results}

The study showed a distinct sociodemographic profile between Brazilian and Portuguese volunteers who responded to the questionnaire (Table 1), the Portuguese showed a higher average age than the Brazilians.

Group 1, with higher weekly fish consumption, presented 124 individuals (13.1\%) with consumption twice or more a week and 293 (31\%) with consumption once a week, totaling 417 (44.1\%) individuals. 
da Silva Maciel E (2016) Cross-sectional study for assessment of fish consumption in terms of the level of physical activity and perception of quality of life in volunteers in Brazil and Portugal

Table 1. Socio-demographic distribution of research participants.

\begin{tabular}{|l|c|c|}
\hline & $\mathbf{n}$ & $\mathbf{\%}$ \\
\hline Gender & & \\
\hline Women & 507 & 53.7 \\
\hline Men & 387 & 41 \\
\hline Missing & 50 & 5.3 \\
\hline Schooling & & \\
\hline Primary school complete & 1 & 1 \\
\hline Middle school dropout & 1 & 1 \\
\hline Middle school complete & 16 & 1.7 \\
\hline College dropout & 202 & 21.4 \\
\hline College complete & 172 & 18.2 \\
\hline Post-graduation & 502 & 53.2 \\
\hline Missing & 50 & 5.3 \\
\hline Marital status & & \\
\hline Single & 485 & 51.4 \\
\hline Married & 347 & 36.8 \\
\hline Widowed & 5 & 5 \\
\hline Divorced & 28 & 3 \\
\hline Other & 29 & 3.1 \\
\hline Missing & 50 & 5.3 \\
\hline Income & & \\
\hline Less than one minimum wage (MW) & 15 & 1.6 \\
\hline 1-2 MW & 59 & 6.3 \\
\hline 2-3 MW & 71 & 7.5 \\
\hline 3-4 MW & 160 & 8.4 \\
\hline 4-6 MW & 108 & 16.9 \\
\hline 6-8 MW & 133 & 14.1 \\
\hline 8-10 MW & 269 & 28.5 \\
\hline Higher than 10 MW & 5.3 \\
\hline Missing & & \\
\hline Missing= lost or left out data & & \\
\hline & & \\
\hline
\end{tabular}

Group 2, with lower weekly fish consumption, had 258 (27.3\%) of individuals with consumption two to three times a month; $130(13.8 \%)$ with consumption once a month; $120(12.7 \%)$ with rare consumption and 19 (2\%) that never consumed fish, totaling 527 (55.8 percent) individuals.

The results showed significant statistical differences between the consumption groups in all variables considered (Table 2).

The values for the mean and sum of ranks show that Group1, formed by volunteers with higher fish consumption, presents higher values in all variables, indicating that more frequent fish consumers in both countries have a more active lifestyle, shown by MET. These consumers also have a better perception of QOL reflected in the domains that compose it.

\section{Discussion}

This study found positive relationships between fish consumption, physical activity and QOL, indicating the possibility of associations between these three variables.

In the investigation of reasons and barriers to fish consumption, some studies have taken into consideration the individual lifestyle choices, health conditions and socio-demographic aspects [11,30,31], which allow concluding that there is a strong component related to fish consumption and life styles, for example, the practice of physical activity [32]. The relationship between fish consumption and the age, in turn, demonstrates that elderly people consume fish more often than younger populations do [11]. Socio-demographic aspects studied in specific regions show that fish consumption is also associated with the presence of children in families, higher age, females and the people living in coastal regions, highlighting the effect of the product availability on the consumption habit [31].

Strengthening the habit seems to be one of the most obvious factors to stimulate consumption, because a habit practiced in the past seems to influence the choices for fish consumption. Thus, effective changes of behavior require affirmative actions that stimulate everyday habits strengthening behavioral choices [33].

Similarly, the habit of fish consumption has been associated with a choice for healthy animal protein in geographically distinct studies [34]. Reduction of cholesterol levels, incidence of stroke, heart disease and possibly Alzheimer's are among the benefits. Fish consumption can boost the cognitive function in adults and help prevent the birth of underweight babies and pre-term labor [10].

Although consumption of other foods was not evaluated in this study, there is a premise that fish consumption is associated with healthier lifestyles, corroborating [15], who identified strong correlation between the consumption of fish and other healthy foods such as vegetables and fruits, based on results observed in the study with Finnish fishermen.

The importance of adopting adequate living habits for health promotion is supported in several studies and shows that healthy eating patterns are associated with significant risk reduction of cardiovascular diseases [35-38].

Table 2. Groups of higher and lower weekly fish consumption in the variables MET and domains of QOL.

\begin{tabular}{|c|c|c|c|c|c|c|c|}
\hline & & $\mathbf{n}$ & $\begin{array}{c}\text { Mean } \\
\text { rank }\end{array}$ & $\begin{array}{l}\text { Sum of } \\
\text { ranks }\end{array}$ & Mean & SD ( $( \pm)$ & $\mathbf{p}$ \\
\hline \multirow[t]{3}{*}{ MET } & Group 1 & 367 & 454.01 & 166622.50 & 2823.61 & 165.18 & 0.012 \\
\hline & Group 2 & 491 & 411.18 & 201888.50 & 2733.64 & 173.33 & \\
\hline & Total & 858 & & & & & \\
\hline \multicolumn{8}{|l|}{ Domains } \\
\hline \multirow[t]{3}{*}{ Physical } & Group 1 & 417 & 508.98 & 212245.50 & 16.80 & 0.11 & $<0.001$ \\
\hline & Group 2 & 527 & 443.63 & 233794.50 & 16.23 & 0.10 & \\
\hline & Total & 944 & & & & & \\
\hline \multirow[t]{3}{*}{ Psychological } & Group 1 & 417 & 526.55 & 219572.50 & 16.07 & 0.09 & $<0.001$ \\
\hline & Group 2 & 527 & 429.73 & 226467.50 & 15.22 & 0.10 & \\
\hline & Total & 944 & & & & & \\
\hline \multirow[t]{3}{*}{ Social relations } & Group 1 & 417 & 513.47 & 214119.00 & 16.15 & 0.13 & $<0.001$ \\
\hline & Group 2 & 527 & 440.08 & 231921.00 & 15.23 & 0.13 & \\
\hline & Total & 944 & & & & & \\
\hline \multirow[t]{3}{*}{ Environment } & Group 1 & 417 & 523.91 & 218472.50 & 14.90 & 0.10 & $<0.001$ \\
\hline & Group 2 & 527 & 431.82 & 227567.50 & 14.12 & 0.09 & \\
\hline & Total & 944 & & & & & \\
\hline \multirow[t]{3}{*}{ General QOL } & Group 1 & 417 & 531.75 & 221740.50 & 16.33 & 0.13 & $<0.001$ \\
\hline & Group 2 & 527 & 425.62 & 224299.50 & 15.19 & 0.13 & \\
\hline & Total & 944 & & & & & \\
\hline
\end{tabular}

MET (Metabolic Equivalent) Group 1: higher fish consumption. Group 2: lower fish consumption

Mean Rank= Mean of points; Sum of Rank= Sum of points; $Q O L=$ Quality of Life 
Based on data obtained through scientific approaches, the American Heart Association (AHA, 2006) recommends that to promote health of the cardiovascular system, it is important to adopt a balanced diet and it highlights that fish should be consumed at least twice a week, also recommended by [39].

A study on fish consumption and $\mathrm{n} 3$ fatty acids and its relation with the risk of coronary heart disease among the Japanese showed that people who consumed less fish, those who ate more fish were less likely to be overweight, but were more likely to be hypertensive and have high alcohol consumption. Compared to the modest fish consumption once a week, a higher consumption was associated with a substantial reduction in the risk of coronary heart disease, mainly non-fatal cardiac events among middle-aged people [39].

Thus, we can affirm that fish consumption may be associated with better health, since it is basic food for diets to control body weight, given that this habit is associated with the consumption of low-caloric foods such as vegetables and fruits. This profile of eating habit also seems to be associated with greater practice of physical activity and therefore greater energy expenditure, as observed in this study and, somehow, it influenced a better perception of QOL.

The relationship of fish consumption with QOL in terms of welfare was investigated by Averina et al. [40], who aimed to prove the relationship between the low consumption of fish, fruit and vegetables with depression, anxiety, sleep disorders and poor QOL in 1,968 men and 1,737 women, in Russia, between 18-90 years of age. The authors showed that the chances of sleep disturbances were $60 \%$ higher for those who consumed fish, fruits or vegetables less frequently and at lower quantity when compared to those who consumed these foods more than once a week. Participants with their nutrition evaluated as "poor" also had significantly higher chances of depression, anxiety, sleep disorders and poor QOL, which shows a beneficial effect of the adherence of these practices and their impact on QOL.

Similarly, a study conducted on a population in New Zealand showed a significant relationship between fish consumption, QOL and mental state of health, indicating that fish consumption was significantly associated with better self-reported mental health state. The results support other studies, where fish consumption is inversely correlated with depression, attributed to the amount of polyunsaturated fatty acids in fish [41].

The positive aspects of fish consumption can also be associated to biological parameters, including low levels of blood cholesterol, triglycerides and glycemia, good cardiovascular response and stress control [42].

This relationship between the adherence to the Mediterranean diet, rich in fish, and the mental and physical self-perception, smoking, BMI, alcohol consumption, schooling, leisure, physical activity and presence of chronic diseases was tested on a sample composed of 3,910 men and 4,285 women, between 35-74 years old, residing in Spain [5].

Although the discussion about this diet model started long ago, only at the end of the last decade the results of epidemiological research were confirmed, indicating its potential beneficial for the prevention of non-transmittable cardiovascular diseases, if it is associated with an active lifestyle [43]. Another interesting evidence lies in the fact that dietary intervention indicates an improvement in the QOL by adopting diets composed of fish, fruits and vegetables [44].

Eating habits are also determined by the age of consumers. This seems to be one of the most discriminatory personal factors to the perception of food quality, that is, changes in the age group of the population, recorded in the last decade, namely reduction of birth rates and increase life expectancy, have caused changes in consumption patterns and eating habits with impacts on the entire food industry [45]. In a study composed of 60 subjects aged between 20-40 years old, to validate a survey to measure fish consumption in Spain, Iceland and Ireland, it was observed that the frequency of fish consumption was higher in Spain, where $70 \%$ of participants consumed fish twice or more per week, while in Iceland, $47 \%$ and Ireland $10 \%$ showed the same frequency of consumption. This shows the power of cultural habits practiced in these countries [4].

It is clear that social and cultural aspects can also provide health benefits. A favorable environment of social support can contribute to better self-perception of health-related QOL [46]. A study conducted on university students in the United Kingdom, for example, showed a strong relationship between the subjective perception of well-being and QOL, related to the behaviors of healthier lifestyles [47].

In a cross-sectional study to evaluate diet and lifestyle in 210 university students in Italy and Spain, 27 years old on average, differences were observed in relation to the consumption of some foods. Italian students consumed cereals more frequently, while Spanish students consumed more fish and vegetables and had higher levels of physical activity [7]. Similarly, the family history of obesity and dietary habits has been linked to lifestyle patterns and risk factors for obesity [48].

Similar results are provided by a study on 19,647 students between 17-30 years old in 21 countries, including Europe, the United States and Asia, about lifestyle with information about smoking, physical activity, alcohol consumption, solar protection, and fruit, fats and fibers intake. Greater satisfaction with life was positively associated with nonsmoking, regular practice of physical exercises, regular consumption of fruits and limitation in fat intake. The results were consistent in all regions for the variables smoking and physical exercises and the relationship between life satisfaction and lifestyle was independent of beliefs in the benefits of behavior to health, that is, active lifestyle and with healthier behaviors influence directly on customer satisfaction and QOL, regardless of knowledge on the subject [42].

Fish effects on health are the main reason for dietary recommendations for fish consumption. However, data show a decrease in consumption among younger people, characteristic of the nutritional transition through which various countries have passed [4].

The evaluation of fish consumption is complex, even in countries with substantial consumption established, which can be attributed to difficulties of the production chain that raises concern about quality and safety of the product. There are collective efforts to overcome this consumption barrier; however, the nutritional quality and perishable characteristics of fish are the main factors that hinder control in the production chain.

On the other hand, as fish and its products are a significant part of a healthy diet, it is important to have a valid and easy-to-apply method to assess its consumption. Questionnaires on eating habits are commonly used in diet studies. Their validation plays an important role in quality assurance of study, because information provided by non-validated questionnaires can lead to inaccurate results and associations.

As limitation of the study, we highlight that it was not performed evaluation of all foods of the diet, which could justify, in part, if the 
da Silva Maciel E (2016) Cross-sectional study for assessment of fish consumption in terms of the level of physical activity and perception of quality of life in volunteers in Brazil and Portugal

fish has been consumed with other foods for health promotion. There is also the possibility of sampling bias, mainly among Brazilians, since access to the Internet and use of its tools are still limiting factors to these types of studies in the country.

\section{Conclusion}

This study shows that individuals that consume fish with higher frequency have better perception of QOL and greater energy expenditure. These characteristics are part of healthy lifestyle habits that contribute to health promotion and the results suggest that, regardless of geographical location, fish consumption appears to be associated to other factors for a more active lifestyle.

\section{Competing interest}

The authors declare that they have no competing interests.

\section{Authors' information}

ESM conceived of the study, and participated in its design and coordination and drafted the manuscript. JGS participated in the design of the study and drafted the manuscript. DMM participated in the design of the study, performed the statistical analysis and drafted the manuscript. FRPQ participated in the design of the study, performed the statistical analysis and drafted the manuscript and drafted the manuscript. MO drafted the manuscript conceived of the study, and participated coordination and helped to draft the manuscript. RV conceived of the study, and participated in its design and coordination and helped to draft the manuscript. All authors read and approved the final manuscript.

\section{Ethical approval}

All procedures performed in this studied involving human participants were in accordance with the ethical standards of the institutional and / or national research committee and with the 1964 Helsinki declaration and its later amendments or comparable ethical standards.

\section{Informed consent}

Informed consent was obtained from individual participants all included in this studied and was approval for the Comitee of ethics in research with human beings of the Escola Superior de Agricultura "Luiz de Queiroz" by University of São Paulo (protocol 087).

\section{Acknowledgement}

The study was supported by a grant from the Cimar project from CAPES (Ciências do Mar 227/2010) and Universidade do Porto Portugal.

\section{References}

1. Rutten GM, Meis JJ, Hendriks MR, Hamers FJ, Veenhof C, et al. (2014) The contribution of lifestyle coaching of overweight patients in primary care to more autonomous motivation for physical activity and healthy dietary behaviour: results of a longitudinal study. International Journal of Behavioral Nutrition and Physical Activity 11: 86 .

2. Maciel ES, Vasconcelos JS, Savay-da-Silva LK, Galvao JA, Sonati JG, et al. (2012) Label Designing For Minimally Processed Tilapia Aiming The Traceability Of The Productive Chain. Boletim do Centro de Pesquisa de Processamento de Alimentos2:30.

3. Hobbs JE (2003) International Agricultural Trade Research Consortium Consumer Demand for Traceability. Working Paper 3.

4. Birgisdottir BE, Kiely M, Martinez JA, Thorsdottir I (2008) Validity of a food frequency questionnaire to assess intake of seafood in adults in three European countries. Food
Control 19:648-653.

5. Muñoz MA, Fíto M, Marrugat J, Covas MI, Schröder H; REGICOR and HERMES investigators (2009) Adherence to the Mediterranean diet is associated with better mental and physical health. Br J Nutr 101: 1821-1827. [Crossref]

6. Tyrovolas S, Panagiotakos DB (2010) The role of Mediterranean type of diet on the development of cancer and cardiovascular disease, in the elderly: a systematic review. Maturitas 65: 122-130.[Crossref]

7. Baldini M, Pasqui F, Bordoni A, MaranesiA (2008) Is the Mediterranean lifestyle still a reality? Evaluation of food consumption and energy expenditure in Italian and Spanish university students. Public Health Nutrition 2:148-155.

8. Honkanen P, Olsen SO, Verplanken B (2005) Intention to consume seafood--the importance of habit. Appetite 45: 161-168.[Crossref]

9. Birch D, Lawley MAA (2010) Conceptual Framework for Investigating Fish Consumption in Australia. In: Proceedings of the 2010 Conference of the Australian and New Zealand Marketing Academy. Australian and New Zealand Marketing Academy (ANZMAC) 1-10.

10. Burger J (2008) Fishing, fish consumption, and awareness about warnings in a university community in central New Jersey in 2007, and comparisons with 2004 Environ Res 108: 107-116.[Crossref]

11. Olsen SO, Scholderer J, Brunsø K, Verbeke W (2007) Exploring the relationship between convenience and fish consumption: a cross-cultural study. Appetite 49: 84-91. [Crossref]

12. Lichtenstein AH, Appel LJ, Brands M, Carnethon M, Daniels S, et al. (2006) Diet and lifestyle recommendations revision 2006: a scientific statement from the American Heart Association Nutrition Committee. Circulation 114:82-96.

13. National Nutrition Council (1998) Finnish Nutrition Recommendations Committee Report ( $7^{\text {the }}$ dtn). Helsinki. Ministry of Agriculture and Forestry.

14. Pieniak Z, Verbeke W, Scholderer J, Brunsø K, Olsen SO (2008) Impact of consumers health beliefs, health involvement and risk perception on fish consumption: A study in five European countries. British Food Journal 110: 898-915.

15. Turunen AW, Männistö S, Suominen AL, Tiittanen P, Verkasalo PK (2011) Fish consumption in relation to other foods in the diet. Br J Nutr 106: 1570-1580.[Crossref]

16. Cardoso C, Lourenço H, Costa S, Gonçalves S, Nunes ML (2013) Survey into the seafood consumption preferences and patterns in the portuguese population. Gender and regional variability. Appetite, Maryland Heights 64:20-31.

17. Zaribaf F, Falahi E, Barak F, Heidari M, Keshteli AH, et al. (2014) Fish consumption is inversely associated with the metabolic syndrome. Eur J Clin Nutr 68: 474-480. [Crossref]

18. Pieniak Z, Verbeke W, Scholderer J (2010) Health-related beliefs and consumer knowledge as determinants of fish consumption. J Hum Nutr Diet 23: 480-488. [Crossref]

19. Tuu HH, Olsen SO, Thao DT, Anh NT (2008) The role of norms in explaining attitudes, intention and consumption of a common food (fish) in Vietnam. Appetite 51: 546-551. [Crossref]

20. Olsen SO, Scholderer J, Brunsø K, Verbeke W (2007) Exploring the relationship between convenience and fish consumption: a cross-cultural study. Appetite 49: 84-91. [Crossref]

21. Maciel ES, Savay-da-Silva LK, Vasconcelos JS, Galvão JA, Sonati JG, et al. (2013) Application of exploratory factor analysis to assess fish consumption in a university community. Ciência e Tecnologia de Alimentos 33: 99-106.

22. Sonoda DY, Campos SK, Cyrino JEP, Shirota R (2012) Fish demand and other animal protein sources in Brazil. Scientia Agricola 69:313-319.

23. Lee C, Moudon AV (2004) Physical Activity and Environment Research in the Health Field: Implications for Urban and Transportation Planning Practice and Research. Journal of Planning Literature 19:147-181.

24. Lee IM, Buchner DM (2008) The importance of walking to public health. Med Sci Sports Exerc 40: S512-518.[Crossref]

25. Bielemann RK, Nuth AG, Hallal PC (2010) Atividadefísica e redução de custospordoençascrônicasaosistemaúnico de saúde. Revista Brasileira de Atividade Física e Saúde15.1.1-10.

26. Maciel ES, Vasconcelos JS, Silva LKSD, Sonati JG, Galvão J, et al. (2013) Designing and validating the methodology for the Internet assessment of fish consumption at a university setting. Food Science and Technology (Campinas) 34: 315-323. 
da Silva Maciel E (2016) Cross-sectional study for assessment of fish consumption in terms of the level of physical activity and perception of quality of life in volunteers in Brazil and Portugal

27. Whoqol Group (1998) The World Health Organization Quality of Life assessment: development and general psychometric properties. Social Science and Medicine, Amsterdam 46:1569-1585.

28. Matsudo SM, Matsudo VKR, Araújo T, Andrade D, Andrade E, et al. (2002)Nível de atividadefísica da população do Estado de São Paulo: análise de acordo com o gênero, idade, nívelsocioeconômico, distribuiçãogeográfica e de conhecimento. Revista Brasileira Ciência e Movimento, Taguatinga 10:41-50.

29. Powers SK, Howley ET (2000)Fisiologia do ExercícioTeoria e AplicaçãoaoCondicionamento e aoDesempenho. São Paulo: Manole 598.

30. Myrland O, Trondsen T, Johnston RS, Lund E (2000) Determinants of seafood consumption in Norway: lifestyle, revealed preferences, and barriers to consumption. Food Quality and Preference 11:169-188.

31. Verbeke W, Vackier I (2005) Individual determinants of fish consumption: application of the theory of planned behaviour. Appetite 44: 67-82.[Crossref]

32. Myrland O, Trondsen T, Johnston RS, Lund E (2000) Determinants of seafood consumption in Norway: lifestyle, revealed preferences, and barriers to consumption. Food Quality and Preference 11:169-188.

33. Honkanen P, Olsen SO, Verplanken B (2005) Intention to consume seafood--the importance of habit. Appetite 45: 161-168.[Crossref]

34. Meas T, Hu W (2014) Consumers' Willingness to Pay for Seafood Attributes: A Multispecies and Multi-state Comparison.

35. Knoops KT, de Groot LC, Kromhout D, Perrin AE, Moreiras-Varela O, et al. (2004) Mediterranean diet, lifestyle factors, and 10-year mortality in elderly European men and women: the HALE project. JAMA 292: 1433-1439.[Crossref]

36. Appel LJ, Moore TJ, Obarzanek E, Vollmer WM, Svetkey LP, et al. (1997) Clinical trial of the effects of dietary patterns on blood pressure. DASH Collaborative Research Group.The New England Journal of Medicine336:1117-1124.

37. Appel LJ, Moore TJ, Obarzanek E, Vollmer WM, Svetkey LP, et al. (2005) The effects of protein, monounsaturated fat, and carbohydrate intake on blood pressure and serum lipids: results of the OmniHeart randomized trial. OmniHeart Collaborative Research Group.JAMA 294:2455-2464.
38. Deforche B, Dyck D, Deliens T, Bourdeaudhuij I (2015) Changes in weight, physical activity, sedentary behaviour and dietary intake during the transition to higher education: a prospective study. International Journal of Behavioral Nutrition and Physical Activity 12:16

39. Iso H, Kobayashi M, Ishihara J, Sasaki S, Okada K, et al. (2006) Intake of fish and n3 fatty acids and risk of coronary heart disease among Japanese: the Japan Public Health Center-Based (JPHC) Study Cohort I. Circulation 113: 195-202.[Crossref]

40. Averina M, Nilssen O, Brenn T, Brox J, Arkhipovsky VL, et al. (2005) Social and lifestyle determinants of depression, anxiety, sleeping disorders and self-evaluated quality of life in Russia. Social Psychiatry and Psychiatric Epidemiology40: 511-518.

41. Silvers KM, Scott KM (2002) Fish consumption and self-reported physical and mental health status. Public Health Nutr 5: 427-431.[Crossref]

42. Grant N, Wardle J, Steptoe A (2009) The relationship between life satisfaction and health behavior: a cross-cultural analysis of young adults. Int J Behav Med 16: 259268.[Crossref]

43. Maciel ES, Oetterer M (2010) O Desafio da AlimentaçãocomoFator de Qualidade de Vida naÚltimaDécada. Inn: VILARTA, R. (org). NovosPadrõesAlimentares e as Relações com osDomínios da Qualidade de Vida e Saúde, Campinas2:18-26.

44. Blank L, Grimsley M, Goyder E, Ellis E, Peters J (2007) Community-based lifestyle interventions: changing behaviour and improving health. J Public Health (Oxf) 29: 236-245.[Crossref]

45. Arima HK (1996)Consumo dos diferentestipos de carne ainda é umaquestão de preçosituaçãoeuropéia. TecnoCarnes, São Paulo 6:1.

46. Molarius A, Berglund K, Eriksson C, Lambe M, Nordström E, et al. (2007) Socioeconomic conditions, lifestyle factors, and self-rated health among men and women in Sweden. Eur J Public Health 17: 125-133.[Crossref]

47. Proctor C, Maltby J, Linley A (2011) Strengths Use as a Predictor of Well-Being and Health-Related Quality of Life. Journal Happiness Studies 12:153-169.

48. Paradis AM, Pérusse L, Vohl MC (2006) Dietary patterns and associated lifestyle in individuals with and without familial history of obesity: a cross-sectional study. International Journal of Behavioral Nutrition and Physical Activity3: 38.

Copyright: (C2016 da Silva Maciel E. This is an open-access article distributed under the terms of the Creative Commons Attribution License, which permits unrestricted use, distribution, and reproduction in any medium, provided the original author and source are credited. 